\title{
Sublingual Misoprostol for labour augmentation
}

\author{
Aruna Verma ${ }^{1}$, Abhilasha Gupta ${ }^{1}$, Monika Kashyap ${ }^{2 *}$
}

${ }^{1}$ Department of Obstetrics and Gynecology, LLRM Medical College, Meerut, Uttar Pradesh, India
${ }^{2}$ Department of Obstetrics and Gynecology, Subharti Medical College, Meerut, Uttar Pradesh, India

Received: 06 March 2019

Accepted: 11 March 2019

\section{*Correspondence:}

Dr. Monika Kashyap,

E-mail: drmonika2k2@gmail.com

Copyright: () the author(s), publisher and licensee Medip Academy. This is an open-access article distributed under the terms of the Creative Commons Attribution Non-Commercial License, which permits unrestricted non-commercial use, distribution, and reproduction in any medium, provided the original work is properly cited.

\section{ABSTRACT}

Background: Labour dystocia is associated with a number of adverse maternal and neonatal outcomes. Augmentation of labour is a commonly used intervention in cases of labour dystocia. Misoprostol is an inexpensive and stable prostaglandin E1analogue. Present study was done to see the effectiveness of sublingual misoprostol for labour augmentation and foeto-maternal outcome.

Methods: Total 100 labouring women of term gestation were taken and divided in two groups: group A (study group) and group B (control group). In study group $25 \mathrm{mcg}$ sublingual misoprostol given 4 hourly till adequate uterine contractions developed, i.e. $>3$ contractions in 10 minutes, each lasting for $40-45$ seconds. A maximum of $200 \mathrm{mcg}$ of misoprostol or 8 doses were used and in group B no drug was given for augmentation of labour. Maternal and foetal outcome were observed in both groups.

Results: Augmentation to delivery interval was very short in group A in comparison to group B. Maternal and foetal outcome were almost same in both groups.

Conclusions: Sublingual misoprostol is a safe and effective drug for augmentation of labour leading to early delivery without any major side effects.

Keywords: Augmentation to delivery interval, Labour augmentation, Sublingual misoprostol

\section{INTRODUCTION}

Labour dystocia is characterised by abnormally slow progress of labour. It can be due to one or more causes, including abnormalities of uterine contractility or the maternal bony pelvis and soft tissues, as well as abnormal foetal presentation, position or development. Labour dystocia is associated with a number of adverse maternal and neonatal outcomes. It can result in a traumatic birth experience and may lead to foetal distress requiring operative birth, either by emergency caesarean section (CS) or vaginal instrumental birth. It may result in perinatal or maternal morbidity or mortality, especially in settings where emergency $\mathrm{CS}$ is not widely available.
Augmentation of labor typically employs oxytocin, although a variety of prostaglandin preparations have been used for either cervical ripening or actual labour induction. Misoprostol is an inexpensive and stable prostaglandin E1analogue. Where electronic oxytocin infusion is not available, low-dose titrated misoprostol may offer a better alternative to an uncontrolled oxytocin infusion to avoid hyperstimulation. ${ }^{1}$

The traditional standard way of augmentation of labour is intravenous oxytocin infusion which has to be titrated according to the severity and intensity of uterine contractions. Oxytocin is given by intravenous infusion and drip rate is calculated as number of drops per minute 
to adjust the dose in $\mathrm{mIU} / \mathrm{ml}$. It has to be regulated by $\mathrm{I} / \mathrm{V}$ regulator and continuous monitoring is required. Inadvertent high dosage can result in uterine hyper stimulation, hypertonus, tachy-systole and foetal distress while under dosage can result in prolonged labour and delayed delivery. ${ }^{2}$ Misoprostol is a synthetic prostaglandin E1 analogue It was initially used to treat peptic ulcers caused by prostaglandin synthetase inhibitors. In April 2002, the U.S. Food and Drug Administration revised the original labelling of misoprostol and approved it for use in pregnancy. ${ }^{3}$ Misoprostol is used off-label for a variety of indications in the practice of obstetrics and gynaecology, including medication abortion, medical management of miscarriage, induction of labour, cervical ripening before surgical procedures, treatment of postpartum hemorrhage. ${ }^{4}$ Effects of misoprostol are dose dependent and include cervical softening and dilation, uterine contractions, nausea, vomiting, diarrhoea, fever, and chills. Its advantages over other synthetic prostaglandin analogues are its low cost, long shelf life, lack of need for refrigeration, and worldwide availability. Being a potent uterotropic and uterotonic agent, misoprostol is a good alternative for labour augmentation. ${ }^{5}$ Sublingual route also ensured adequate absorption and effective blood levels of misoprostol needed for labour augmentation, so misoprostol was given sublingually rather than vaginally or orally in present study. The study was done to see for the effectiveness of sublingual misoprostol for labour augmentation and foeto-maternal outcome.

\section{METHODS}

The presented study was conducted in the department of Obstetrics and Gynaecology, LLRM Medical College, Meerut from 1st January 2013 to 31st December 2014 (1 year). The type of study is case control study. All pregnant women who had no medical illness and had gestation between 37-42 weeks gestation with a cephalic singleton pregnancy in spontaneous labour (either latent phase or in active phase of 1st stage of labour) were enrolled for the study.

\section{Inclusion criteria}

- Singleton pregnancy

- Cephalic Presentation

- Gestational age $\geq 37$ to $\leq 42$ weeks

- Reactive non-stress test

- Adequate pelvis and no cephalo-pelvic disproportion.

\section{Exclusion criteria}

- Uterine tachysystole or hypertonicity

- A non-reassuring non-stress test

- Meconium stained amniotic fluid

- Previous uterine incision

- Macrosomia i.e. Estimated fetal weight of $4500 \mathrm{gm}$.

- $\quad$ Parity $>5$

- Any contraindication to prostaglandins
- Mal-presentation

- $\quad$ severe renal/ hepatic dysfunction

- Placenta previa.

Written and informed consent about the drug being given for augmentation of labour and probable side effects was taken.

Total 100 cases were taken and divided into two groups:

Group A (Study group) 50 patients in latent or active phase of first stage of labour with inadequate uterine contractions were taken and their labour was augmented with 25 ug sublingual misoprostol every 4 hourly.

Group B (control group) 50 patients were enrolled with no augmentation of labour with any drug.

All patients had detailed clinical history and examination and baseline investigations were done. After taking informed consent, labour of study group was augmented with sublingual misoprostol $25 \mathrm{mcg} 4$ hourly till adequate uterine contractions developed, i.e. $>3$ contractions in 10 minutes, each lasting for $40-45$ seconds. A maximum of $200 \mathrm{mcg}$ of misoprostol or 8 doses were used.

\section{RESULTS}

Demographic parameters- mean age in group A was 26.3 years and group B was 26.7 ( $\mathrm{p}$ value 0.11 ), mean gestation of delivery was 38.3 in group $\mathrm{A}$ and 38.1 in group B (p value 0.42 ) and mean parity was 2.3 in group A and 2.1 in group B (p value 0.42 ), so both the groups were comparable. Most of the cases developed adequate uterine contractions with three doses of drug. The mean dose required for labour augmentation in primigravida was $75 \mathrm{mcg}$ and that in multigravida was $50 \mathrm{mcg}$ (Figure 1).

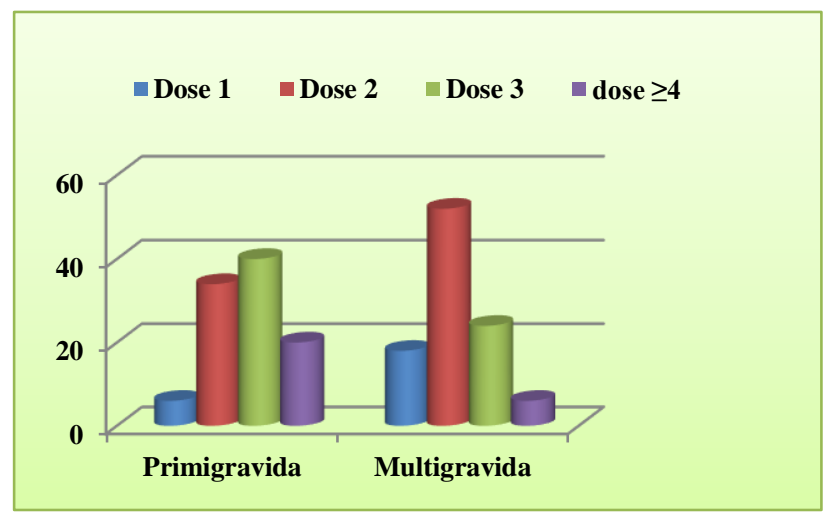

Figure 1: Number of doses required for augmentation of labor.

Mean duration of $1^{\text {st }}$ stage in primigravida and multigravida, the augmentation group was significantly shorter $(\mathrm{p}<0.05)$ when compared with that of the control group $(353.5 \pm 80.6 \mathrm{~min}$ vs $389.4 \pm 78.5 \mathrm{~min}$ in 
primigravida and $235.2 \pm 76.7 \mathrm{~min}$ vs $342.4 \pm 63.5 \mathrm{~min}$ in multigravida) (Table 1).

Table 1: Duration of active phase of $1^{\text {st }}$ stage of labor.

\begin{tabular}{|c|c|c|c|c|}
\hline & \multirow[t]{2}{*}{ Groups } & \multicolumn{2}{|c|}{$\begin{array}{l}\text { Duration of } \\
\text { active phase } \\
\text { of first stage } \\
\text { (min) }\end{array}$} & \multirow[t]{2}{*}{$\begin{array}{l}\text { p } \\
\text { value }\end{array}$} \\
\hline & & Mean & SD & \\
\hline \multirow[t]{2}{*}{ Primigravida } & $\begin{array}{l}\text { Augmentation } \\
\text { group }\end{array}$ & 353.5 & \pm 80.6 & \multirow[t]{2}{*}{$<0.05$} \\
\hline & Control group & 389.4 & \pm 78.5 & \\
\hline \multirow[t]{2}{*}{ Multigravida } & $\begin{array}{l}\text { Augmentation } \\
\text { group }\end{array}$ & 235.2 & \pm 76.7 & \multirow[t]{2}{*}{$<0.05$} \\
\hline & Control group & 342.4 & \pm 63.5 & \\
\hline
\end{tabular}

Mean rate of cervical dilatation in $\mathrm{cm} / \mathrm{hr}$ in primigravida was significantly more in augmentation group when compared with control group $(1.41 \pm 0.29 \mathrm{~cm} / \mathrm{hr}$ vs 1.09 $0.32 \mathrm{~cm} / \mathrm{hr}$ ). Similar was the case with multigravida $(1.92 \pm 0.64 \mathrm{~cm} / \mathrm{hr}$ vs $1.28 \pm 0.45 \mathrm{~cm} / \mathrm{hr}$ ) (Table 2).

Table 2: Rate of cervical dilatation in $\mathrm{cm} / \mathrm{hr}$.

\begin{tabular}{|c|c|c|c|c|}
\hline & \multirow[t]{2}{*}{ Groups } & \multicolumn{2}{|c|}{$\begin{array}{l}\text { Rate of } \\
\text { cervical } \\
\text { dilatation } \\
(\mathrm{cm} / \mathrm{hr})\end{array}$} & \multirow[t]{2}{*}{$\begin{array}{l}\mathrm{p} \\
\text { value }\end{array}$} \\
\hline & & Mean & $\begin{array}{l}\text { SD } \\
\text { ratio }\end{array}$ & \\
\hline \multirow[t]{2}{*}{ Primigravida } & $\begin{array}{l}\text { Augmentation } \\
\text { group }\end{array}$ & 1.41 & \pm 0.29 & \multirow[t]{2}{*}{$<0.05$} \\
\hline & Control group & 1.09 & \pm 0.32 & \\
\hline \multirow[t]{2}{*}{ Multigravida } & $\begin{array}{l}\text { Augmentation } \\
\text { group }\end{array}$ & 1.92 & \pm 0.64 & \multirow[t]{2}{*}{$<0.05$} \\
\hline & Control group & 1.28 & \pm 0.45 & \\
\hline
\end{tabular}

There was no significant difference in the duration of second and third stage of labour in augmentation and control group.

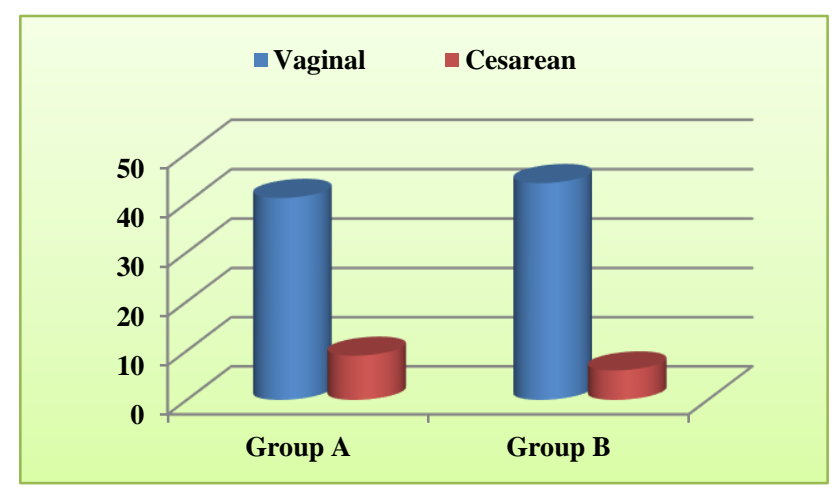

Figure 2: Mode of delivery.

$82 \%$ of patients delivered vaginally in the augmentation group and $88 \%$ in the control group incidence of caesarean section though found statistically not significant. (Figure 2). Foetal out come when compared between two groups, the difference was found not significant. In misoprostol group maternal side effects like nausea, vomiting was seen when compared to that of the control group but for that no patient needed significant intervention.

\section{DISCUSSION}

The purpose of this study was to see the safety of misoprostol for augmentation of labour. As we know that misoprostol has been identified as a safe, inexpensive and easily administered option for the induction of labour, with satisfactory results. We were concerned that the effects of misoprostol might be substantially different in women with pre-existing uterine activity. In Cochrane review two randomized trials with a total of 581 women each comparing different regimens of titrated oral misoprostol with intravenous oxytocin in augmentation of labour. One study compared $20 \mathrm{mcg}$ doses of misoprostol dissolved in water (repeated every hour up to four hours, after which the dose was increased to $40 \mathrm{mcg}$ per hour up to a maximum total dose of $1600 \mathrm{mcg}$ ), while the second study gave women $75 \mathrm{mcg}$ doses (repeated after four hours provided there were no adverse effects observed). Neither trial reported maternal death, severe maternal morbidity, or foetal/neonatal mortality outcomes. Only a few foetal/neonatal morbidity outcomes were considered, none of which were significantly different between groups. Neither trial reported significantly higher rates of caesarean section (CS) in the oral misoprostol group. The only significant differences between groups related to uterine hyper stimulation (without foetal heart rate changes), and results were not consistent in the two trials. ${ }^{1}$ A randomized controlled trial done by Bleich AT et al. on oral misoprostol for labour augmentation 350 women were randomized, $176(50 \%)$ to oral misoprostol and $174(50 \%)$ to intravenous oxytocin. In study they found oral misoprostol as effective agent for augmentation of labor. There were no significant differences in maternal or neonatal outcomes. ${ }^{6}$ Study done by Sujata et al did study comparing low dose sublingual vs. oral misoprostol in induction of labour and they found that although both drugs reduced induction to delivery interval, but it was much lesser in sublingual group and was statistically significant and none of the group had significant abnormal neonatal outcome or maternal side effects. ${ }^{7}$ In a study done by Swapnil Wilson et al. comparing Oxytocin to oral Misoprostol for augmentation of labour found that patients in the active phase of labour with poor uterine contraction and slow dilatation of the cervix, both the agents i.e. oral misoprostol and I.V. oxytocin shortens the duration of labour effectively. ${ }^{8}$ In a study done by Patel A. et al. also concluded that misoprostol seems to be an effective alternative to oxytocin augmentation of labor. ${ }^{9}$ Study done Shi-Yann Cheng et al. concluded in their study that titrated oral misoprostol solution is easier to administer than titrated intravenous oxytocin, it is worth conducting these treatment regimens for labour induction or 
augmentation. It is an ideal alternative to traditional dinoprostone or oxytocin for labour induction or augmentation. ${ }^{10}$ Study done by Maliha et al. also concluded that oral misoprostol is observed to be similar to intravenous oxytocin infusion in labour augmentation and may be an alternative to the traditional oxytocin. ${ }^{11}$ In present study we also found that sublingual misoprostol effectively shortens the augmentation to delivery interval with very minimal side effects and no significant difference in maternal and neonatal outcome. Although the use of oral misoprostol for labour augmentation is not recommended by WHO for labour augmentation where skilled attendants are not available. ${ }^{12}$ In future to standardize the dose of misoprostol for augmentation of labour few studies are done and are ongoing. A study done by Kathryn $\mathrm{S}$ et al. included healthy, nulliparous women in active labour and diagnosed with arrest of dilation were enrolled in cohorts of 10 at a time. Five regimens were studied: (1) $25 \mu \mathrm{g}$ every 4 hours, (2) $50 \mu \mathrm{g}$ every 4 hours, (3) $100 \mu \mathrm{g}$ every 4 hours, (4) $50 \mu \mathrm{g}$ every 2 hours, and (5) $75 \mu \mathrm{g}$ every 4 hours. They concluded that an oral dose of $75 \mu \mathrm{g}$ of misoprostol given at a 4-hour interval for a maximum of 2 doses is the highest tolerated dose. ${ }^{13}$ A randomized controlled trial by Daniele Sofia Moraes et al. is ongoing to see if we can use Misoprostol administered sublingually at a dose of $12.5 \mu \mathrm{g}$ versus vaginally at a dose of $25 \mu \mathrm{g}$ for the induction of full-term labour to reduce the risk of hyper-tonicity and tachysystole and the results are awaited. ${ }^{14}$

\section{CONCLUSION}

The present study shows that sublingual misoprostol is a safe and effective drug for augmentation of labour leading to early delivery without any major side effects or third stage complications. But to standardise the ideal regimen of misoprostol for labour augmentation result of randomized controlled trials are awaited.

\section{ACKNOWLEDGMENTS}

Authors would like to thank all patients and doctors of department of Obstetrics and Gynaecology, LLRM Medical College involved in the study.

Funding: No funding sources

Conflict of interest: None declared

Ethical approval: The study was approved by the Institutional Ethics Committee

\section{REFERENCES}

1. Vogel JP, West HM, Dowswell T. Titrated oral misoprostol for augmenting labour to improve maternal and neonatal outcomes. Cochrane Database of Systematic Reviews. 2013;9:CD010648.
2. Selin L, Wallin G, Berg M. Dystocia in labour-risk factors, management and outcome: a retrospective observational study in a Swedish setting. Acta Obstetricia Et Gynecologica Scandinavica. 2008;87(2):216-21.

3. New U.S. Food and Drug Administration labelling on Cytotec (misoprostol) use and pregnancy. ACOG Committee Opinion No. 283.Obstet Gynecol 2003; 101(5):1049-50.

4. Rebecca Allen, Barbara M O' Brien. Uses of Misoprostol in Obstetrics and Gynaecology. Rev Obstet Gynecol. 2009;2(3):159-68.

5. Ho M, Cheng SY, Li TS. Oral Misoprostol solution compared with intravenous oxytocin for labour augmentation. Obstet Gynecol. 2010;116(3):612-18.

6. Bleich AT1, Villano KS, Lo JY, Alexander JM, McIntire DD, Leveno KJ. Oral misoprostol for labor augmentation: a randomized controlled trial. Obstet Gynecol. 2011;118(6):1255-60.

7. Siwatch S, Doke G, Kalra J, Bagga R. Sublingual vs. oral misoprostol for labour induction. J Postgrad Med Edu Res. 2014;48(1):33-36.

8. Wilson S, Das S. Oxytocin versus oral Misoprostol for augmentation of labour, associated complications and effect on neonatal wellbeing. Int $\mathbf{J}$ Reprod Contracept Obstet Gynecol. 2018;7(8):3338-42.

9. Patel A, Gilles JM, Moffett D, Mahram R, Diro M, Burkett G. Can misoprostol be interchanged with oxytocin for augmentation of labor?. Obstet Gynecol. 2000;95(4):S10.

10. Cheng SY. Individualized misoprostol dosing for labor induction or augmentation: A review. World J Obstet Gynecol. 2013;2(4):80-6.

11. Maliha S, Shagufta SS, Sobia NM. Augmentation of labour- A Comparison of oral misoprostol and intravenous titrated oxytocin infusion, J Rawalpindi Med College (JRMC); 2013;17(2):247-50.

12. WHO recommendation on the use of oral misoprostol for labour augmentation. Available at https://extranet.who.int/rhl/topics/preconceptionpregnancy-childbirth-and-postpartum-care/careduring-childbirth/care-during-labour-1st-stage/whorecommendation-use-oral-misoprostol-labouraugmentation

13. Villano KS, Lo JY, Alexander JM, McIntire DD, Leveno KJ. A dose-finding study of oral misoprostol for labor augmentation. Am J Obstet Gynecol. 2011;204(6):560-e1.

14. Gattás DS, da Silva Junior JR, Souza AS, Feitosa FE, de Amorim MM. Misoprostol administered sublingually at a dose of $12.5 \mu \mathrm{g}$ versus vaginally at a dose of $25 \mu \mathrm{g}$ for the induction of full-term labor: a randomized controlled trial protocol. Reproduct Health. 2018;15(1):65.

Cite this article as: Verma A, Gupta A, Kashyap M. Sublingual Misoprostol for labour augmentation. Int J Reprod Contracept Obstet Gynecol 2019;8:1300-3. 